\title{
Parents knowledge and oral hygiene level of kindergarten students
}

\author{
Vania Arista Muljadi*, Henry Mandalas**, Grace Monica* \\ *Department of Public Health Faculty of Dentistry Maranatha Christian University, Indonesia \\ **Department of Periodontics Faculty of Dentistry Maranatha Christian University, Indonesia
}

\begin{abstract}
Introduction: Parents knowledge related to oral health behaviour in children. Parents introduced the habit of tooth brushing to their children and how to maintain good oral hygiene. The purpose of this study was to describe parents knowledge about tooth brushing and oral hygiene level in the kindergarten students. Methods: The study design was cross sectional research and descriptive observational. This study was conducted towards 25 students of Gymboree and Kidsville at Bandung, Indonesia, which consisted of 14 boys (56\%) and 11 girls (44\%). The data collection was done by giving questionnaires to parents and examination of student's oral hygiene level by using PHP index. Results: Generally parents already have the good knowledge that supports the children oral hygiene level, but there were still $52 \%$ of parents who does not use the recommended techniques to brush the outer surface of the teeth and $64 \%$ of parents who does not use the recommended techniques to brush the tooth surface that face to the cheek. The oral hygiene level of Gymboree and Kidsville students were very good $0 \%(0), 32 \%$ good $(0.1$ 1.7), $60 \%$ medium (1.8-3.4), and $8 \%$ bad (3.5-5.0). Awareness of parents about tooth brushing and oral hygiene level of children were generally adequate, but were not fulfilling the standards of oral health recommended by dentist. Conclusion: Parents knowledge about oral hygiene were generally good and the oral hygiene of kindergarten student were in medium range.
\end{abstract}

Keywords: Parents knowledge, how to brush your teeth, oral hygiene levels

P-ISSN 1979-0201, e-ISSN 2549-6212 Available from:http://jurnal.unpad.ac.id/pjd/index

DOI:http://dx.doi.org/10.24198/pjd.vol29no2.12308

Submission: Feb 2017 Publishing: July 2017

\section{INTRODUCTION}

Oral health is an important aspect of public health, it can be defined as a state of oral condition health that allows an individual to eat, talk, and socialize without getting sickness, discomfort, or shame and can contribute to the general welfare. ${ }^{1}$
Knowledge of oral health is regarded as an important prerequisite in the practice of healthrelated, and there is a relationship between good knowledge and better oral health. ${ }^{1,2}$ Parents play an important role in creating oral hygiene and prevention of dental and mouth disease in children. ${ }^{3}$ Child's oral health can be affected by 
parental knowledge, attitudes and cultural beliefs and also be related to lifestyle and behavior of parents in maintaining oral health. Children's oral health will affect their health to adulthood. ${ }^{4}$

The initial concept in maintaining oral hygiene is to removing plaque and infectious agents that can cause gum disease. ${ }^{3}$ Plaque may be defined as a soft deposit formed from the attachment of biofilms on tooth surfaces or hard surfaces in the oral cavity. Plaque is the leading cause of disease in the oral cavity such as caries and periodontal disease. ${ }^{5,6}$ Prevention of the diseases of the oral cavity is by removing plaque with many methods, but the mechanical method using a toothbrush is the main method in maintaining good oral hygiene. ${ }^{7}$

Toothbrushing is a simple and effective way to remove plaque thus preventing the occurrence of caries and periodontal disease. The toothbrushing habit should be introduced to the child by parents from an early age, so this habit will be brought into adulthood. ${ }^{4}$ According to the American Academy of Pediatric Dentistry, parents should brushing their child's teeth that are still at preschool age or until the age of six years, and to assist children in brushing their teeth until the child is eight years old. Maintain oral hygiene and healthy teeth since the child or in preschool children (3-6 years) are important because of the high prevalence of caries. ${ }^{8,9}$

\section{METHODS}

This research used descriptive observasional and cross sectional methods. Dental and oral health examination were performed to obtain data on oral hygiene in children, so the level of oral hygiene of children can be determined. Assessment of oral hygiene levels was measured according to the Patient Hygiene Performance (PHP) index. Research subjects examined were categorized according to scale based on score, including: very good (0), good (0.1-1.7), Medium (1.8 -3.4), Bad (3.5-5.0), and after that the frequency distribution and percentage were calculated.

Data collection was also done by giving questionnaires about the knowledge of parents in maintain their children oral health. Questions on the questionnaire include the following: The role of parents in guiding the child, the use of tools and techniques used to brush teeth.

\section{RESULTS}

The population in this study were the parents and children attending Gymboree and Kidsville kindergarten at Bandung, Indonesia. The data collection was done by giving questionnaires to parents and examination of student's oral hygiene level by using PHP index. The total number of the research subjects were twenty five children, consisted of 14 boys (56\%) and 11 girls (44\%),

Table 1. Overview of plaque index of the research subjects

\begin{tabular}{ccc}
\hline No & Plaque Index & Frequency (\%) \\
\hline 1 & Very Good (0) & $0(0 \%)$ \\
2 & Good $(0.1-1.7)$ & $8(32 \%)$ \\
3 & Medium $(1.8-3.4)$ & $15(60 \%)$ \\
4 & Bad $(3.5-5.0)$ & $2(8 \%)$ \\
\hline Total & & $25 .(100 \%)$ \\
\hline
\end{tabular}

Table 2. Distribution of plaque on research subjects

\begin{tabular}{|c|c|c|c|c|c|c|}
\hline \multirow{2}{*}{$\begin{array}{l}\text { Research } \\
\text { subject }\end{array}$} & \multicolumn{6}{|c|}{ plaque distribution } \\
\hline & 54 & 51 & 64 & 74 & 71 & 84 \\
\hline 1 & 2 & 3 & 3 & 3 & 2 & 3 \\
\hline 2 & 1 & 3 & 2 & 1 & 2 & 1 \\
\hline 3 & 1 & 2 & 1 & 4 & 2 & 4 \\
\hline 4 & 3 & 3 & 3 & 1 & 1 & 1 \\
\hline 5 & 1 & 3 & 2 & 1 & 2 & 1 \\
\hline 6 & 2 & 1 & 1 & 3 & 1 & 2 \\
\hline 7 & 2 & 1 & 1 & 2 & 2 & 2 \\
\hline 8 & 3 & 5 & 4 & 3 & 3 & 3 \\
\hline 9 & 4 & 2 & 2 & 1 & 1 & 3 \\
\hline 10 & 4 & 2 & 3 & 2 & 2 & 3 \\
\hline 11 & 4 & 2 & 2 & 2 & 2 & 3 \\
\hline 12 & 4 & 2 & 3 & 3 & 2 & 4 \\
\hline 13 & 3 & 2 & 3 & 4 & 2 & 5 \\
\hline 14 & 1 & 3 & 2 & 5 & 1 & 1 \\
\hline 15 & 1 & 1 & 3 & 2 & 1 & 2 \\
\hline 16 & 1 & 3 & 2 & 2 & 2 & 2 \\
\hline 17 & 1 & 4 & 1 & 1 & 2 & 1 \\
\hline 18 & 2 & 1 & 2 & 2 & 1 & 2 \\
\hline 19 & 2 & 2 & 2 & 2 & 2 & 3 \\
\hline 20 & 1 & 2 & 2 & 1 & 2 & 1 \\
\hline 21 & 5 & 1 & 5 & 3 & 1 & 2 \\
\hline 22 & 3 & 1 & 5 & 3 & 1 & 2 \\
\hline 23 & 5 & 5 & 5 & 1 & 2 & 1 \\
\hline 24 & 3 & 5 & 3 & 3 & 1 & 3 \\
\hline 25 & 5 & 2 & 5 & 4 & 3 & 3 \\
\hline Average & 3 & 2 & 3 & 2 & 2 & 2 \\
\hline
\end{tabular}


between $4-5$ years old. There were 11 subjects aged 4 years $(44 \%)$ and 14 subjects aged 5 years (56\%).

Table 1 shows the plaque index by using Patient Hygiene Performance (PHP) index. Research subjects in general have plaque index which was included in Medium category $(1,8-3,4)$ that were as many as 14 people $(60 \%)$, the rest were included in category of Good $(0,1-1,7)$ that were 9 people (32\%), meanwhile included in the category of Bad (3.5-5,0) as many as 2 people $(8 \%)$ and there were no subject of study included in the category of Very Good (0).

Table 2 shows the distribution of plaque on each research subject. From the average of plaque distribution, mostly were found on the tooth 54 and tooth 64, with the average plaques score on tooth surfaces was 3 , whereas in teeth $51,74,71$ and 84 had an average plaques score on tooth surface was 2 .

Table 3. Overview of parents knowledge about tooth brushing

\begin{tabular}{|c|c|}
\hline Knowledge of parents & $\begin{array}{c}\text { Frequency } \\
(\%)\end{array}$ \\
\hline \multicolumn{2}{|l|}{ Parents help children toothbrushing } \\
\hline - $\quad$ Always & $17(68 \%)$ \\
\hline - $\quad$ Sometimes & $8(32 \%)$ \\
\hline - $\quad$ Never & $0(0 \%)$ \\
\hline \multicolumn{2}{|l|}{ Using Child's toothbrush } \\
\hline - Yes & $25(100 \%)$ \\
\hline - $\quad$ No & $0(0 \%)$ \\
\hline \multicolumn{2}{|l|}{ Using Child's toothpaste } \\
\hline - Yes & $24(96 \%)$ \\
\hline - $\quad$ No & $1(4 \%)$ \\
\hline \multicolumn{2}{|l|}{ Using toothpaste as much as pea size } \\
\hline - Yes & $15(60 \%)$ \\
\hline - $\quad$ No & $10(40 \%)$ \\
\hline \multicolumn{2}{|c|}{$\begin{array}{l}\text { The bristles position is affixed perpendicular } \\
\text { to the surface of the tooth while brushing }\end{array}$} \\
\hline - Yes & $25(100 \%)$ \\
\hline - $\quad$ No & $0(0 \%)$ \\
\hline \multicolumn{2}{|c|}{$\begin{array}{l}\text { Teeth is held in the position of biting (jaw in } \\
\text { the closing state) when brushing teeth }\end{array}$} \\
\hline - Yes & $17(68 \%)$ \\
\hline - $\quad$ No & $8(32 \%)$ \\
\hline \multicolumn{2}{|c|}{ Brushing the outer surface of the tooth } \\
\hline - Yes & $22(88 \%)$ \\
\hline - $\quad$ No & $3(12 \%)$ \\
\hline \multicolumn{2}{|l|}{ Brushing the inner surfaces of the teeth } \\
\hline - Yes & $23(92 \%)$ \\
\hline - $\quad$ No & $2(8 \%)$ \\
\hline \multicolumn{2}{|c|}{ Brushing the back surface of the front teeth } \\
\hline - Yes & $22(88 \%)$ \\
\hline - $\quad$ No & $3(12 \%)$ \\
\hline \multicolumn{2}{|l|}{$\begin{array}{l}\text { Brushing the tooth surface close to } \\
\text { the cheek }\end{array}$} \\
\hline - Yes & $25(100 \%)$ \\
\hline - $\quad$ No & $0(0 \%)$ \\
\hline \multicolumn{2}{|c|}{ Brushing the tooth surface close to the tongue } \\
\hline - Yes & $18(72 \%)$ \\
\hline - $\quad$ No & $7(28 \%)$ \\
\hline \multicolumn{2}{|c|}{ Brushing the occlusal surface of the tooth } \\
\hline - Yes & $25(100 \%)$ \\
\hline - $\quad$ No & $0(0 \%)$ \\
\hline \multicolumn{2}{|l|}{ Brushing tongue } \\
\hline - Yes & $15(60 \%)$ \\
\hline - $\quad$ No & $10(40 \%)$ \\
\hline
\end{tabular}

\begin{tabular}{|c|c|}
\hline Knowledge of parents & $\begin{array}{l}\text { Frequency } \\
\text { (\%) }\end{array}$ \\
\hline \multicolumn{2}{|c|}{$\begin{array}{l}\text { The best technique to brush the outer surfaces } \\
\text { of teeth }\end{array}$} \\
\hline - Circular & $12(48 \%)$ \\
\hline - Horizontal & $13(52 \%)$ \\
\hline \multicolumn{2}{|c|}{$\begin{array}{l}\text { The best technique to brush the back surface } \\
\text { of the front teeth }\end{array}$} \\
\hline - Ups and down & $21(84 \%)$ \\
\hline - Horizontal & $4(16 \%)$ \\
\hline \multicolumn{2}{|c|}{$\begin{array}{l}\text { The best technique to brush the tooth surface } \\
\text { is close to the cheek }\end{array}$} \\
\hline - Circular & $9(36 \%)$ \\
\hline - Horizontal & $16(64 \%)$ \\
\hline \multicolumn{2}{|c|}{$\begin{array}{l}\text { The most excellent technique for brushing the } \\
\text { occlusal surface }\end{array}$} \\
\hline - $\quad$ Back and forth & $24(96 \%)$ \\
\hline - Horizontal & $1(4 \%)$ \\
\hline \multicolumn{2}{|c|}{ The best technique to brush the tongue } \\
\hline - One way & $19(76 \%)$ \\
\hline - Two-way direction & $6(24 \%)$ \\
\hline \multicolumn{2}{|c|}{$\begin{array}{l}\text { Need to brush the same surface on each tooth } \\
\text { continuously for at least } 5 \text { seconds }\end{array}$} \\
\hline - Yes & $19(76 \%)$ \\
\hline - $\quad$ No & $6(24 \%)$ \\
\hline \multicolumn{2}{|c|}{$\begin{array}{l}\text { Time to brush your teeth for } 2-3 \text { minutes is } \\
\text { enough }\end{array}$} \\
\hline - Yes & $23(92 \%)$ \\
\hline - $\quad$ No & $2(8 \%)$ \\
\hline \multicolumn{2}{|l|}{ Need to rinse after brushing } \\
\hline - Yes & $25(100 \%)$ \\
\hline - $\quad$ No & $0(0 \%)$ \\
\hline \multicolumn{2}{|c|}{$\begin{array}{l}\text { Need to rinse many times after brushing your } \\
\text { teeth }\end{array}$} \\
\hline - $\quad$ No & $15(60 \%)$ \\
\hline - $\quad$ Yes & $10(40 \%)$ \\
\hline \multicolumn{2}{|c|}{$\begin{array}{l}\text { Need to clean the bristles with running water } \\
\text { after use }\end{array}$} \\
\hline - Yes & $23(92 \%)$ \\
\hline - $\quad$ No & $2(8 \%)$ \\
\hline \multicolumn{2}{|c|}{$\begin{array}{l}\text { Need to replace toothbrush in a certain period } \\
\text { of time }\end{array}$} \\
\hline - Yes & $25(100 \%)$ \\
\hline - $\quad$ No & $0(0 \%)$ \\
\hline
\end{tabular}


Table 3 shows the distribution of parents answers to fill out the questionnaires about parents knowledge about tooth brushing and there were 25 respondents (parents) who fill in the questionnaire given.

\section{DISCUSSION}

The results of this study indicate that half of the total research subjects who have been examined on their oral hygiene using Patient hygiene Performance (PHP)index, included in the category of medium $(60 \%)$, some children included in good category (32\%), very little in bad category (8\%) and none of which were included in the category very well. This is thought to be related to the age of the examined child, ranging from 4-5 years. Children of this age did not yet have self-awareness, good motor skills and knowledge in the effort to maintain oral hygiene, ${ }^{10}$ so that the role of parents is very important as the control and guarding children to keep his oral hygiene. ${ }^{11}$

Research conducted by Ministry of Research, Technology and Higher Education of the Republic of Indonesia (Ristekdikti) in 2013 shows that caries rates in Indonesian children are still very high, presumably due to a lack of awareness of dental and oral hygiene maintenance and low levels of oral hygiene. ${ }^{12}$ The level of oral hygiene can be determined through the examination of dental plaque.

Based on Table 2 on plaque distribution in children found score 3 mostly in upper posterior teeth of 54 and 64 , whereas in the anterior and posterior lower teeth is known lower plaque score. It is thought to be related to anatomy and tooth position. The posterior posterior anatomy has more vulnerable areas of caries such as pits and fissures, and the posterior upper posterior position is more difficult to reach so often missed when brushing teeth. While the anterior and posterior mandibular teeth are easy to see, they are easy to reach and the anatomy has more dental immune areas.

The habits of eating soft and cariogenic foods are also suspected to be the concomitant factor of plaque enhancement. Results of research ever conducted by Riana et $a l^{13}$, about the habits of eating cariogenic foods in students is known to be quite high and the most commonly affected caries area is the occlusal surface (96.3\%). If a high plaque score is left then in the future it is expected to increase the risk of occlusal caries. ${ }^{13}$

The technique used when brushing teeth is said to have an effect on the effectiveness and the results obtained. Proper brushing techniques will play a role in preventing caries. Parents are expected to have a good knowledge of how to brush teeth, techniques and tools needed to obtain good oral hygiene levels. ${ }^{11}$

Based on the results of this study of parents knowledge of child brushing habits, it was found that: most parents always help children in brushing teeth, almost all use brush and toothpaste specially for children, but the techniques used by parents not according to recommended method. To improve the degree of oral hygiene of children, it is necessary to improve knowledge both for parents and teachers. The role of teachers is as a companion when children in school with School Health Program (UKS), while the role of parents more when the child is at home. Dental and oral health training can not be done once, but requires regular and structured training, based on research by Anne et al..$^{14}$, initial training alone in teachers has not been able to influence changes in student behavior. ${ }^{14}$

\section{CONCLUSION}

Parents knowledge about oral hygiene were generally good but not in accordance with recommended dental and oral health standards. The level of oral hygiene of kindergarten student were in medium range.

\section{REFERENCES}

1. Carneiro L, Kabulwa M, Makyao M, Mrosso G, Choum R. Oral health knowledge and practices of secondary school students, Tanga, Tanzania. Int J Dentis 2011:1-6. doi:10.1155/2011/806258.

2. Bangash MFK, Khan J, Hanif A. Oral hygiene practice and awareness among pakistanis in riyadh, Saudi Arabia. Pakistan Oral \& Dent J 2013;33(2):350-3.

3. Sultan D, L Al-Yahya, Al-Anzi A. Oral health knowledge and attitudes among parents in Kuwait. Elective Project Study Course No. 703 [online series] 2013 [cited 2015 Sep 
20];Available from: http://www.hsc.edu.kw/ fod/research/PDF_Files/DS_LY_13.pdf/fod/ research/P.

4. Lopes MF. To brush or not to brush-Parental knowledge about their child's oral health. [Serial online] 2014 [cited 2015 Sep 2015]; Available from URL: http://sigarra.up.pt/ fmdup/pt/publs_pesquisa.show_publ_ file?pct_gdoc_id=12884\&pct_publ_id=97893.

5. Carranza FA, Takei HH, Newman MG. Carranza's clinical periodontology, $9^{\text {th }}$ ed. St. Louis: WB Saunders Co.; 2002. p. 97.

6. Seneviratne CJ, Zhang CF, Samaranayake LP. Dental plaque biofilm in oral health and disease. [online series] 2011 [cited $2015 \mathrm{Sep}$ 15]; Available from:http:www.ncbi.nlm.gov/ pubmed/22319749.

7. Alnakhli A, Omar OM. Effectiveness of two instruction methods in improving tooth brushing skills in children: A clinical trial. BJMMR 2016;17(6):1-5.

8. Pullishery F, Ganesh SP, Rekha S. Parental attitudes and tooth brushing habits in preschool children in Mangalore, Karnataka: A cross-sectional study. Int J Clin Pediat Dentist 2013;6(3):156-60.

9. American Academy of Pediatric Dentistry: Fast facts. [online series] 2014 [cited 01 Oct 2015];
Available from: www.aapd.org/assets/1/7/ FastFacts.pdf.

10. Wahyuni IS, Hidayat W, Nuraeny N, Andisetyanto P, Zenab Y. Studi pendahuluan prevalensi kelainan gigi dan lesi mulut pada anak sekolah dasar alam pelopor Bandung. Prosiding Dies Natalis 57 Fakultas Kedokteran Gigi Universitas Padjadjaran: 2017. p. 172-80.

11. de Castilhoa ARF, Mialheb FL, Barbosac TdS, Puppin-Rontanid RM. Influence of family environment on children's oral health: A systematic review. J Pediatr (Rio J) 2013;89(2):116-23.

12. Badan Penelitian dan Pengembangan Kesehatan Kementerian Kesehatan RI. Basic Health Research (Riset Kesehatan Dasar); Jakarta: Ministry of Health; 2013. p. 110-9.

13. Wardani R, Zubaedah C, Setiawan AS. Occlusal caries risk assessment using cariogram analysis in student aged 11-12 years. Padjadjaran J Dent 2017;29(1):14-21. Available from: http: // dx.doi.org/10.24198/pjd.vol29no1.11344.

14. Suwargiani AA, Wardani R, Suryanti N, Setiawan AS. The impact of initial oral health training on teacher's knowledge, attitudes, and actions change. Padjadjaran J Dentist 2017;29(1):27-32. Available from:http:// dx.doi.org/10.24198/pjd.vol29no1.11596. 